\title{
Inhibition of the autophagy flux by gingerol enhances TRAIL-induced tumor cell death
}

\author{
UDDIN MD. NAZIM ${ }^{1,2}$, JAE-KYO JEONG $^{1,2}$, JAE-WON SEOL $^{1,2}$, JIN HUR $^{1,2}$, \\ SEONG-KUG EO ${ }^{1,2}$, JOHN-HWA LEE ${ }^{1,2}$ and SANG-YOUEL PARK ${ }^{1,2}$ \\ ${ }^{1}$ Biosafety Research Institute, College of Veterinary Medicine, ${ }^{2}$ Department of Bioactive Material Sciences and \\ Research Center of Bioactive Materials, Chonbuk National University, Jeonju, Jeonbuk 561-756, Republic of Korea
}

Received January 14, 2015; Accepted March 4, 2015

DOI: $10.3892 /$ or.2015.3869

\begin{abstract}
Tumor necrosis factor-related apoptosis-inducing ligand (TRAIL) is a primary anticancer agent and a member of the tumor necrosis factor family that selectively induces apoptosis in various tumor cells, but not in normal cells. Gingerol is a major ginger component with anti-inflammatory and anti-tumorigenic activities. Autophagy flux is the complete process of autophagy, in which the autophagosomes are lysed by lysosomes. The role of autophagy in cell death or cell survival is controversial. A549 adenocarcinoma cells are TRAIL-resistant. In the present study, we showed that treatment with TRAIL slightly induced cell death, but gingerol treatment enhanced the TRAIL-induced cell death in human lung cancer cells. The combination of gingerol and TRAIL increased accumulation of microtubule-associated protein light chain 3-II and p62, confirming the inhibited autophagy flux. Collectively, our results suggest that gingerol sensitizes human lung cancer cells to TRAIL-induced apoptosis by inhibiting the autophagy flux.
\end{abstract}

\section{Introduction}

Tumor necrosis factor-related apoptosis-inducing ligand (TRAIL) is a cytokine, a member of the tumor necrosis factor family and a selective inducer of apoptosis in a range of tumor cells (1). TRAIL binding to its receptors results in activating the death receptors (DR) including DR4 or DR5 to induce the receptor trimerization and recruit the Fas-associated death domain protein, which leads to the activation of the caspase cascade (caspase-8, $-9,-10$, and -3 ) to transmit the cell death signal $(2,3)$. TRAIL is a promising anticancer agent with the ability to selectively induce apoptosis in various tumors, but not in most normal cells (4). However, A549 cells show resistance to the apoptotic effects of TRAIL (5).

Correspondence to: Professor Sang-Youel Park, Biosafety Research Institute, College of Veterinary Medicine, Chonbuk National University, Jeonju, Jeonbuk 561-756, Republic of Korea

E-mail: sypark@chonbuk.ac.kr

Key words: gingerol, TRAIL, apoptosis, autophagy flux
The biochemical and pharmacological properties of gingerol, a natural ginger component, include antioxidant, antiinflammatory, and anti-tumorigenic activities (6,7). Gingerol treatment results in mitochondrial damage and inhibits cell survival pathways in colorectal cancer cells (8). Gingerol has an anti-tumorigenic effect by inducing apoptosis in tumor cells (9-11). However, the exact apoptosis-inducing molecular mechanism of gingerol remains unknown.

Autophagy is a self-degradation mechanism responsible for cell death and survival (12). Autophagy flux is the complete autophagy process, starting with formation of autophagosomes around the cargo, fusion of the autophagosome with lysosomes, and degradation and recycling of the cargo $(13,14)$. Microtubuleassociated protein 1 light chain $3 \beta$ (also called ATG8), which is a ubiquitin-like protein, is necessary for autophagosome formation and is widely used as an autophagy marker $(15,16)$. p62/SQSTM1, also known as a ubiquitin-binding protein, integrates into the autophagosome by directly attaching to LC3-II and is degraded by autophagy (17). Inhibiting autophagy increases p62 levels (18). Many anticancer drugs upregulate autophagy, leading to uncontrolled tumors (19-21). Recent studies have shown that pharmacologically or genetically inhibiting autophagy increases the effects of radiotherapy and chemotherapy (22-24), suggesting that inhibiting autophagy is a favorable cancer treatment strategy. Anti-malarial and anti-rheumatoid arthritis drugs (chloroquine) act as autophagy inhibitors during cancer therapy $(25,26)$. Chloroquine prevents lysosome acidification and fuses with autophagosomes as a result of degradation of the metabolic stress products, thereby inducing apoptosis (27-30).

Our study determined that gingerol sensitized TRAILinduced apoptosis in TRAIL-resistant A549 cells by inhibiting the autophagy flux. Treatment with gingerol or TRAIL alone did not influence cell death; thus, we examined whether co-treatment of gingerol with TRAIL had more of an effect on A549 lung adenocarcinoma cells. We investigated the sensitizing effect of gingerol on TRAIL-induced apoptosis in A549 lung adenocarcinoma cells by inhibiting the autophagy flux.

\section{Materials and methods}

Cell culture. Cancer cells originating from lung (A549) tumors were obtained from the American Type Culture Collection 
(Global Bioresource Center, Manassas, VA, USA). The cells were cultured in RPMI-1640 medium (Gibco-BRL, Grand Island, NY, USA) supplemented with $10 \%(\mathrm{v} / \mathrm{v})$ fetal bovine serum and antibiotics (100 $\mu \mathrm{g} / \mathrm{ml}$ penicillin-streptomycin). The cell cultures were incubated in an atmosphere containing $5 \% \mathrm{CO}_{2}$ at $37^{\circ} \mathrm{C}$.

Reagents. Recombinant gingerol was purchased from Santa Cruz Biotechnology, Inc. (Santa Cruz, CA, USA). TRAIL $(100 \mathrm{ng} / \mathrm{ml}$ ) was purchased from Abfrontier (Geumcheon-gu, Seoul, South Korea) and chloroquine $(10 \mu \mathrm{M})$ was purchased from Sigma-Aldrich (St. Louis, MO, USA).

Cell viability test. The A549 cells were plated at a density of $1.0 \times 10^{4}$ cells in 12 -well plates and were incubated at $37^{\circ} \mathrm{C}$ for $24 \mathrm{~h}$. The A549 cells were pretreated with gingerol in a dose-dependent manner $(0,10,20$, and $40 \mu \mathrm{M})$. After the 12 -h gingerol pretreatment, the recombinant TRAIL $(100 \mathrm{ng} / \mathrm{ml})$ protein was added and co-incubated for $2 \mathrm{~h}$. The cells were also pretreated with chloroquine $(10 \mu \mathrm{M})$ for $1 \mathrm{~h}$ followed by gingerol treatment. The cell morphology was photographed under a microscope (inverted microscope; Nikon, Japan) and the cell viability was determined using the crystal violet staining method. The cells were stained with a staining solution ( $0.5 \%$ crystal violet in $30 \%$ ethanol and $3 \%$ formaldehyde) for $10 \mathrm{~min}$ at room temperature, washed 4 times with PBS and dried. Then, the cells were lysed with a $1 \%$ SDS solution and measured at an absorbance of $550 \mathrm{~nm}$. The cell viability was calculated from relative dye intensity and it was compared with the control.

Western blot assay. The A549 cell lysates were prepared by harvesting the cells, washing them in cold PBS, resuspending in a lysis buffer [25 mM HEPES (pH 7.4), $100 \mathrm{mM}$ EDTA, $5 \mathrm{mM} \mathrm{MgCl}_{2}, 0.1 \mathrm{mM}$ DTT, and a protease inhibitor mixture], and sonicating the lysate. The proteins $(35 \mu \mathrm{g})$ were separated on a $10-15 \%$ SDS gel and transferred to a nitrocellulose membrane. After $1 \mathrm{~h}$ of incubation with a 1:1,000 primary antibody dilution buffer (1\% milk with PBS-Tween-20), the membranes were developed by enhanced chemiluminescence using a secondary antibody. The antibodies used for immunoblotting were LC3 (Novus Biologicals, Littleton, CO, USA), anti-p62 (Millipore Corp., Milford, MA, USA), cleaved caspase-3 (Cell Signaling Technology, Danvers, MA, USA), and $\beta$-actin (Sigma-Aldrich). Images were examined using a Fusion-FX7 imaging system (Vilber Lourmat, Marne-la-Vallée, France).

Immunocytochemistry (ICC). The A549 cell lines were cultured on a glass coverslip and treated with gingerol, chloroquine and/or TRAIL, washed with PBS and fixed with 3-4\% paraformaldehyde in PBS for $15 \mathrm{~min}$ at room temperature. The cells were then washed twice in ice cold PBS, the samples were incubated for $10 \mathrm{~min}$ in PBS containing 0.25\% Triton $\mathrm{X}-100$ and the cells were washed with PBS 3 times for $5 \mathrm{~min}$. The cells were blocked with $1 \%$ BSA in PBST for $30 \mathrm{~min}$, incubated with the primary antibodies (LC3 and anti-p62, diluted in $1 \%$ BSA in PBST) in a humidified chamber for $1 \mathrm{~h}$ at room temperature or overnight at $4{ }^{\circ} \mathrm{C}$, the solution was decanted and then the cells were washed with PBS 3 times
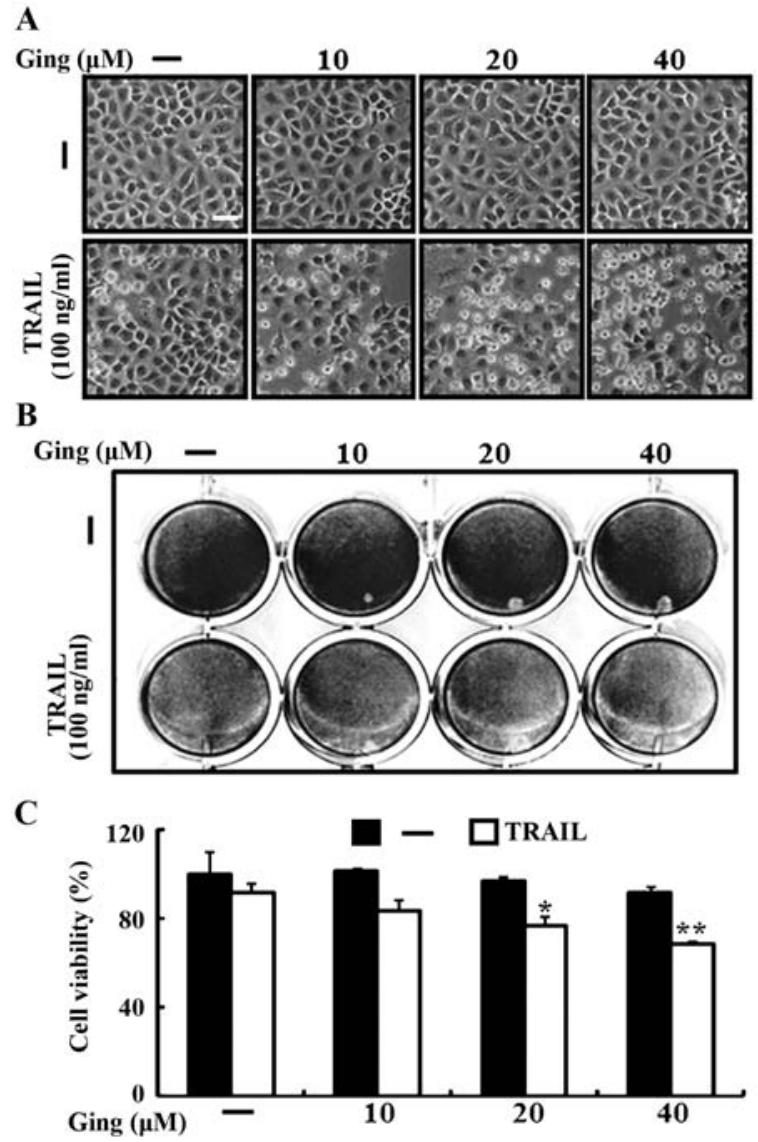

Figure 1. Gingerol enhanced TRAIL-induced apoptosis in A549 cells. The A549 cells were pretreated with gingerol in a dose-dependent manner $(0,10$, 20 , and $40 \mu \mathrm{M}$ ) for $12 \mathrm{~h}$ and were then treated with $100 \mathrm{ng} / \mathrm{ml}$ of TRAIL protein for an additional $2 \mathrm{~h}$. The cell morphology was photographed by a light microscope (x100) (A), and cell viability was measured by a crystal violet assay (B). The bar graph indicates the average density of the crystal violet dye $(\mathrm{C}) .{ }^{*} \mathrm{P}<0.05,{ }^{* *} \mathrm{P}<0.01$, significant differences between the control and each treatment group. Ging, gingerol; TRAIL, tumor necrosis factor (TNF)-related apoptosis-inducing ligand.

for $5 \mathrm{~min}$. The cells were incubated again with the secondary antibody in $1 \%$ BSA for $1 \mathrm{~h}$ at room temperature in the dark and the secondary antibody solution was decanted and washed with PBS 3 times for $5 \mathrm{~min}$. The cells were incubated with DAPI for 1 min and rinsed with PBS. Finally, the cells were mounted with a fluorescent mounting medium and visualized via a fluorescence microscope.

Statistical analysis. The unpaired t-test or the Welch's correction were used for comparison between two groups. For multiple comparison, the one-way ANOVA followed by the Tukey-Kramer's test was used. All statistical analysis was performed using GraphPad Prism software. Results were considered to be statistically significant for values ${ }^{\text {" }} \mathrm{P}<0.05$, ${ }^{* * *} \mathrm{P}<0.01$.

\section{Results}

Gingerol enhances TRAIL-induced apoptosis in A549 cells. We investigated the effects of gingerol co-treatment on TRAIL-induced apoptosis in A549 lung adenocarcinoma cells. The cells were pretreated with the indicated doses of 

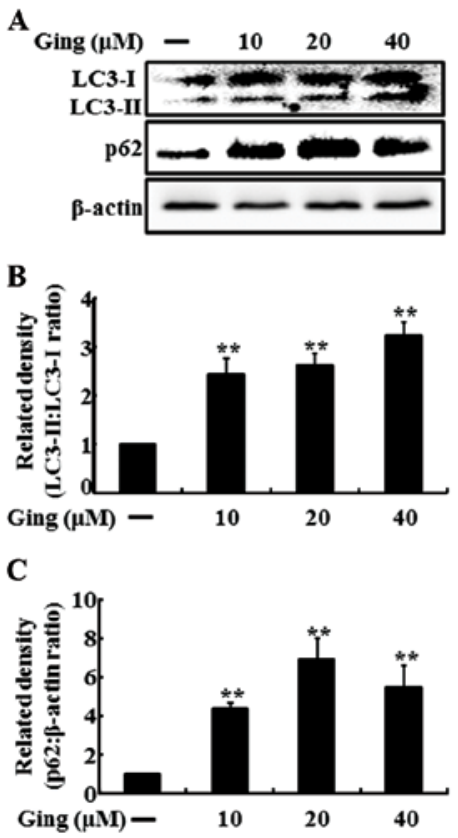
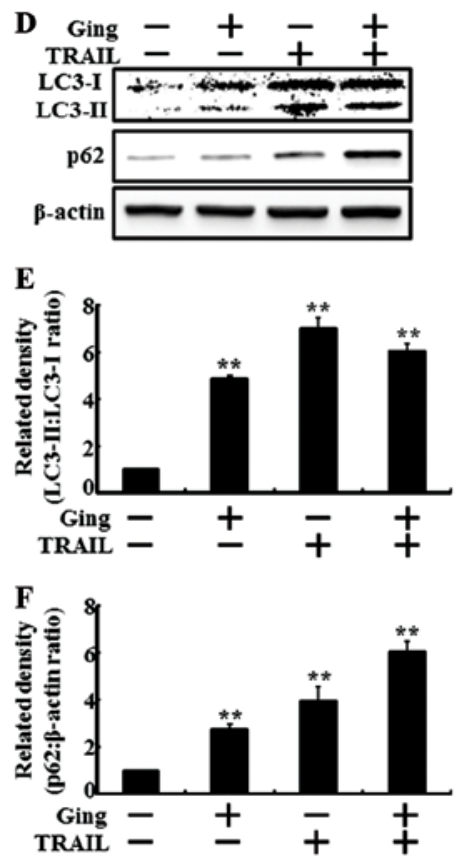

G

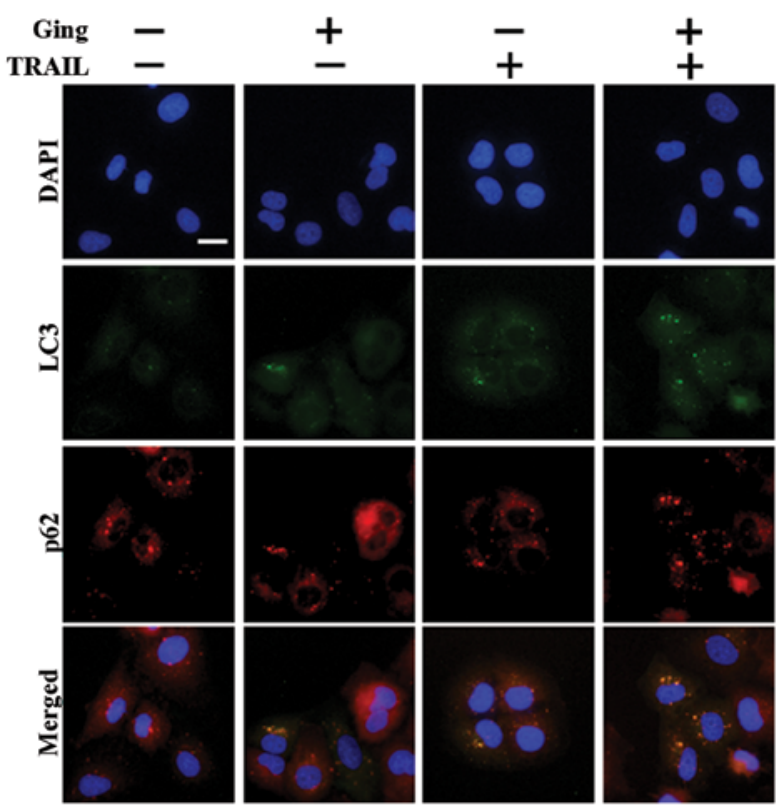

Figure 2. Gingerol inhibits the autophagy flux in lung adenocarcinoma cells. (A) The A549 adenocarcinoma cells were pretreated with gingerol in a dose-dependent manner $(0,10,20$, and $40 \mu \mathrm{M})$ for $12 \mathrm{~h}$. The cells were harvested and analyzed by western blot analysis to determine the LC3-II and p62 expression levels (A). The bar graph indicates the averages of the LC3-II/LC3-I and p62/ $\beta$-actin ratio (B and C). The A549 cells were pretreated with gingerol $(40 \mu \mathrm{M})$ for $12 \mathrm{~h}$ and then exposed to $100 \mathrm{ng} / \mathrm{ml}$ TRAIL for an additional 2-h. Western blot analysis was performed to determine the LC3-II and p62 expression levels (D). The bar graph indicates the averages of the vLC3-II/LC3-I and p62/ $\beta$-actin ratio (E and F). $\beta$-actin was used as the loading control. Representative immunocytochemistry in the A549 cells after co-treatment with gingerol (12 h) and $100 \mathrm{ng} / \mathrm{ml}$ of TRAIL ( $2 \mathrm{~h})(\mathrm{G}){ }^{* * *} \mathrm{P}<0.01$, significant difference between the control and each treatment group. Ging, gingerol; TRAIL, tumor necrosis factor (TNF)-related apoptosis-inducing ligand.

gingerol for $12 \mathrm{~h}$ and were treated with the TRAIL protein for an additional 2-h. We photographed the cells to investigate the cell morphological changes using a light microscope and the crystal violet assay. As shown in Fig. 1, TRAIL treatment alone either did not or only slightly induced cell death, indicating that the A549 cells are highly resistant to TRAILinduced apoptosis, but gingerol enhanced TRAIL-induced apoptosis in a dose-dependent manner. The cell morphology also supported this enhanced effect of gingerol, showing that the combination of TRAIL and gingerol enhanced the number of the apoptotic cells compared with that of gingerol or TRAIL alone (Fig. 1A). The TRAIL and gingerol co-treatment reduced cell viability and significantly increased apoptosis in the A549 cells (Fig. 1B and C). These results indicate that gingerol increased TRAIL-induced apoptosis in TRAIL-resistant A549 cells.

Gingerol inhibits autophagy flux in lung adenocarcinoma cells. To investigate the effect of gingerol on autophagy flux, we treated the A549 cells with gingerol in a dose-dependent manner for $12 \mathrm{~h}$ and with TRAIL for an additional 2-h. All the cell lysates were subjected to western blot analysis to determine changes in LC3-II and p62. LC3-II expression is a marker for complete autophagosomes. p62 is a ubiquitin-binding protein involved in lysosome- or proteasome-dependent protein degradation. Treatment with increasing gingerol concentrations for $12 \mathrm{~h}$ resulted in a dose-dependent increase in LC3-II and p62 levels in the A549 cells (Fig. 2A). The density graphs of the protein levels in LC3-II and p62 were also dose-dependently changed (Fig. 2B and C). The combined TRAIL and gingerol treatment enhanced the LC3-II and p62 levels compared with those of gingerol or TRAIL alone (Fig. 2D). The density graphs of the protein levels in LC3-II and p62 were also increased in combined TRAIL and gingerol treatment (Fig. 2E and F). The ICC results showed that co-treatment of gingerol with TRAIL enhanced LC3-II and p62 protein levels compared to those of gingerol or TRAIL treatment alone (Fig. 2G).

Gingerol-mediated enhancement of TRAIL-induced cell death by inhibiting autophagy flux. We used chloroquine to investigate the effect of gingerol-mediated enhancement of TRAIL-induced cell death in A549 lung adenocarcinoma cells. The cells were pretreated with the indicated gingerol doses for $12 \mathrm{~h}$ and then treated with the TRAIL protein for an additional 2-h. The cells were also pretreated with chloroquine for $1 \mathrm{~h}$ followed by gingerol treatment. We photographed the cells to investigate the morphological changes using a light microscope and the crystal violet assay. As shown in Fig. 3, treating the A549 cells with either TRAIL or gingerol alone slightly enhanced cell death, but combined treatment with TRAIL and chloroquine strongly enhanced cell death. The cell morphology results also supported this enhanced cell death effect by TRAIL and chloroquine compared to that of gingerol or TRAIL alone (Fig. 3A). The combined treatment of chloroquine and TRAIL reduced cell viability and significantly increased cell death in the A549 lung cancer cells (Fig. 3B and C). These results indicate that gingerol-mediated enhanced TRAIL-induced cell death by inhibiting the autophagy flux.

Gingerol-mediated enhancement of the TRAIL-induced apoptotic pathway by inhibiting the autophagy flux. We 


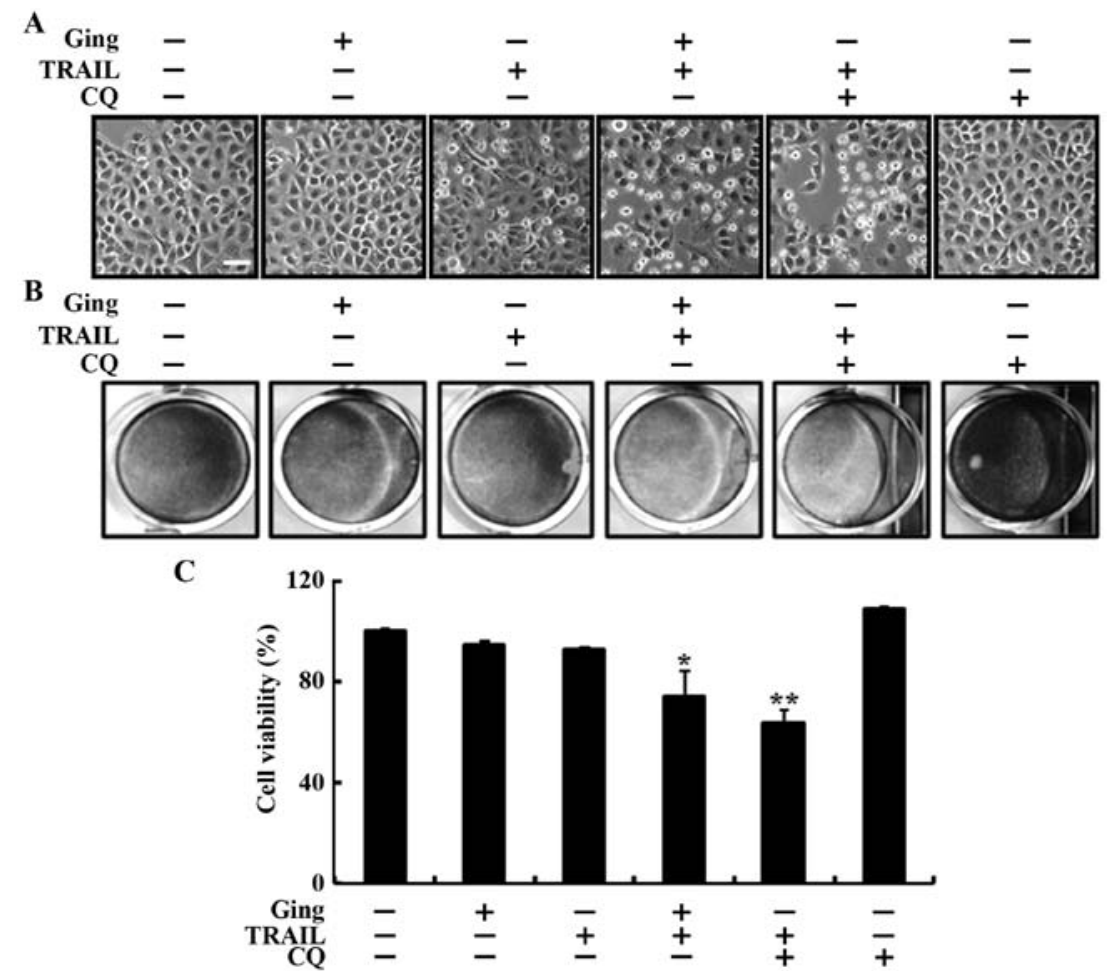

Figure 3. Gingerol mediates enhancement of TRAIL-induced cell death by inhibiting the autophagy flux. The A549 adenocarcinoma cells were pretreated with gingerol $(40 \mu \mathrm{M})$ for $12 \mathrm{~h}$ and then treated with $100 \mathrm{ng} / \mathrm{ml}$ of the TRAIL protein for an additional 2-h. The cells were also pretreated with chloroquine for $1 \mathrm{~h}$ followed by gingerol treatment. The cell morphology was photographed by a light microscope (x100) (A). The cell viability was measured by the crystal violet assay (B). The bar graph indicates the average density of the crystal violet dye (C). ${ }^{*} \mathrm{P}<0.05,{ }^{* * *} \mathrm{P}<0.01$, significant difference between the control and each treatment group. Ging, gingerol; TRAIL, tumor necrosis factor (TNF)-related apoptosis-inducing ligand; CQ, chloroquine.
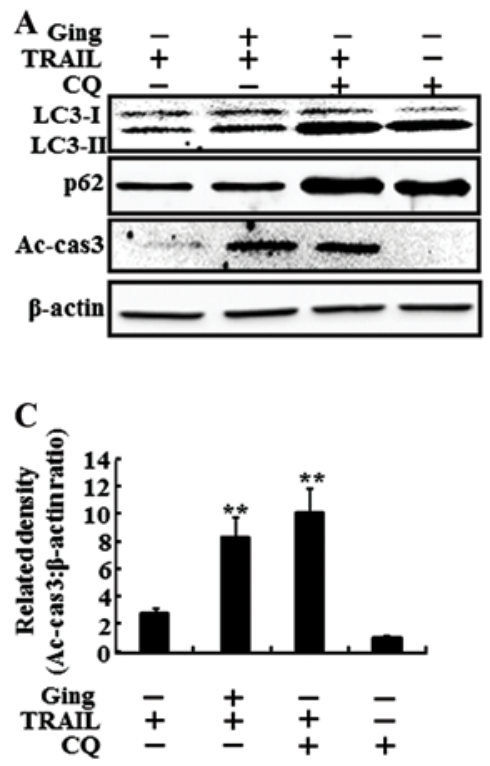

B

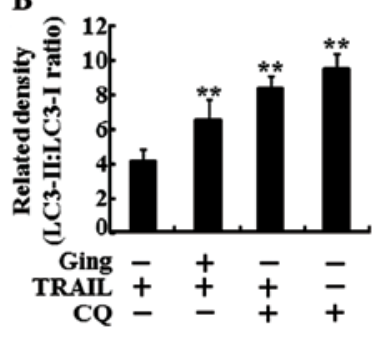

D

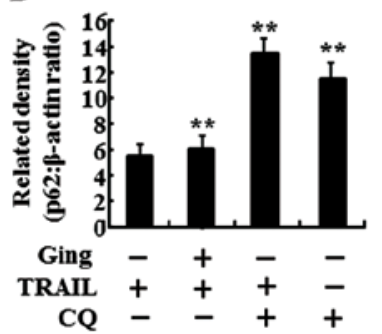

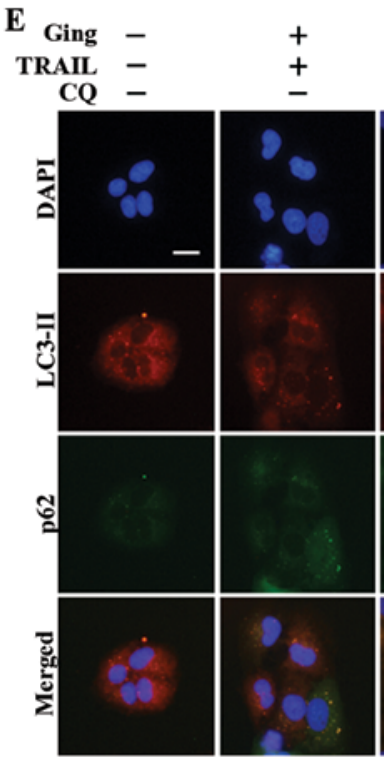

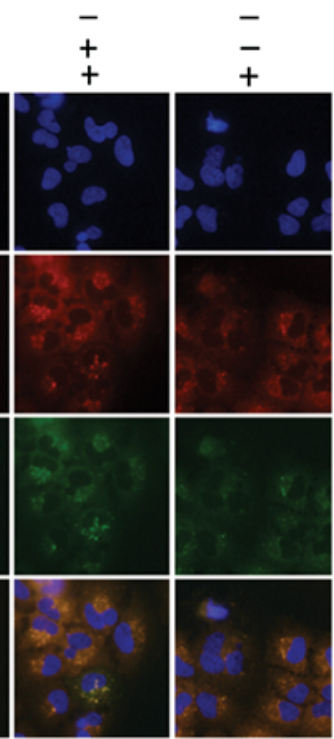

Figure 4. Gingerol mediates enhancement of the TRAIL-induced apoptotic pathway by inhibiting the autophagy flux. The A549 cells were pretreated with gingerol $(40 \mu \mathrm{M})$ for $12 \mathrm{~h}$ and then treated with $100 \mathrm{ng} / \mathrm{ml}$ of the TRAIL protein for an additional $2-\mathrm{h}$. The cells were also pretreated with chloroquine for $1 \mathrm{~h}$ followed by gingerol treatment. The cells were harvested and analyzed by western blot analysis to determine the LC3-II, p62 and activated caspase-3 expression levels (A). The bar graph indicates the averages of the LC3-II/LC3-I, Ac-cas3/ $\beta$-actin and p62/ $\beta$-actin ratio (B, C and D). $\beta$-actin was used as the loading control. Representative immunocytochemistry in the A549 cells after co-treatment with chloroquine $(1 \mathrm{~h})$, gingerol $(12 \mathrm{~h})$ and $100 \mathrm{ng} / \mathrm{ml}$ of TRAIL (2 h) (E). ${ }^{* *} \mathrm{P}<0.01$, significant difference between the control and each treatment group. Ging, gingerol; TRAIL, tumor necrosis factor (TNF)-related apoptosis-inducing ligand; CQ, chloroquine; Ac-cas3, activated-caspase-3.

investigated the effect of gingerol-mediated enhancement of the TRAIL-induced apoptotic pathway by inhibiting the autophagy flux with chloroquine. The cells were pretreated with the indicated doses of gingerol for $12 \mathrm{~h}$ and were treated with the TRAIL protein for an additional 2-h. The cells were also pretreated with chloroquine $(10 \mu \mathrm{M})$ for $1 \mathrm{~h}$ followed 
by gingerol treatment. As shown in Fig. 4A, the gingerol and TRAIL co-treatment increased the LC3-II level. Treatment with chloroquine alone also greatly increased the LC3-II level. The combined treatment of TRAIL and chloroquine resulted in more LC3-II compared to that of gingerol or TRAIL alone. The gingerol and TRAIL co-treatment increased the p62 level. Furthermore, the combined treatment of TRAIL and chloroquine increased the p62 levels more than that of chloroquine or TRAIL alone, confirming that gingerol inhibits the autophagy flux in A549 cells. The gingerol and TRAIL co-treatment inhibited cell viability and significantly enhanced apoptosis in the A549 cells. These results were confirmed by the intracellular apoptosis indicator cleaved caspase-3. The density graphs of the protein levels in LC3-II, caspase- 3 and p62 were also changed in combined TRAIL and chloroquine treatment (Fig. 4B, C and D). The ICC results showed that the TRAIL and chloroquine combined treatment increased the LC3-II and p62 levels compared to those of chloroquine or gingerol alone (Fig. 4E).

\section{Discussion}

The purpose of the present study was to investigate the function of gingerol and gingerol and TRAIL co-treatment on the inhibition of autophagy flux and the regulation of TRAIL-mediated sensitivity by gingerol in A549 human adenocarcinoma cells. The results suggest that gingerol sensitizes TRAIL-induced apoptosis in A549 lung adenocarcinoma cells by inhibiting autophagy flux.

TRAIL is a promising anticancer agent with the ability to selectively trigger apoptosis in various tumors, but not in most normal cells. The therapeutic potential of TRAIL is being tested in various clinical trials (31). Induction of apoptosis requires additional treatment with other chemotherapeutic agents, which however, damage the normal cells. Gingerol has antiemetic, antipyretic, anticancer and anti-inflammatory activities $(32,33)$. Furthermore, it is not significantly toxic to normal cells, but it reduces rat liver tumor grow th and induces apoptosis via a TNF- $\alpha$-mediated pathway (34). Autophagy is a self-degradation mechanism responsible for cell death or survival. Autophagy flux is the complete process of autophagy, and A549 cell proliferation was impaired by chloroquine, which is an autophagy inhibitor, suggesting that A549 cells may be dependent on the autophagy pathway.

treatment enhanced the LC3-II and p62 levels compared to that in the control by inhibiting the autophagy flux ( $\mathrm{F}$ Jin et al (5) showed that the A549 cells are resistant to the apoptotic effects of TRAIL. We observed that gingerol or TRAIL alone either did not or only slightly induced death of the A549 adenocarcinoma cells. However, the combined treatment of gingerol and TRAIL strongly induced death in the A549 cells (Fig. 1). Some studies have shown that TRAIL induces autophagy in various types of cancer cells $(35,36)$. However, our results indicate that treatment with increasing concentrations of gingerol or TRAIL alone resulted in a dose-dependent increase in the LC3-II and p62 levels in the A549 adenocarcinoma cells. The combined TRAIL and gingerol ig. 2). Gingerol promotes TRAIL-induced apoptosis in gastric cancer cells (37). Pharmacological or genetic inhi- bition of autophagy induces death in various cancer cells, and we investigated the sensitivity of A549 cell proliferation to pharmacological inhibition of autophagy with chloroquine. Co-treatment with gingerol and TRAIL increased the LC3-II and p62 levels. Furthermore, TRAIL and chloroquine combined treatment increased the LC3-II and p62 levels compared to those of chloroquine or gingerol alone. These results were confirmed by the intracellular apoptosis indicator cleaved caspase-3 (Figs. 3 and 4).

In conclusion, gingerol induces apoptosis in A549 cells by inhibiting the autophagy flux. The combination of gingerol and TRAIL strongly enhanced apoptosis in TRAIL-resistant A549 cells, suggesting that gingerol sensitizes TRAIL-induced apoptosis in TRAIL-resistant A549 adenocarcinoma cells by inhibiting the autophagy flux.

\section{Acknowledgements}

This study was supported by a grant from the National Research Foundation of Korea (NRF), funded by the Korean Government (MISP) (no. 2013R1A4A1069486).

\section{References}

1. Gonzalvez F and Ashkenazi A: New insights into apoptosis signaling by Apo2L/TRAIL. Oncogene 29: 4752-4765, 2010.

2. Aggarwal BB: Signalling pathways of the TNF superfamily: A double-edged sword. Nat Rev Immunol 3: 745-756, 2003.

3. Bellail AC, Tse MC, Song JH, Phuphanich S, Olson JJ, Sun SY and Hao C: DR5-mediated DISC controls caspase-8 cleavage and initiation of apoptosis in human glioblastomas. J Cell Mol Med 14: 1303-1317, 2010.

4. Bellail AC, Qi L, Mulligan P, Chhabra V and Hao C: TRAIL agonists on clinical trials for cancer therapy: The promises and the challenges. Rev Recent Clin Trials 4: 34-41, 2009.

5. Jin CY, Park C, Hwang HJ, Kim GY, Choi BT, Kim WJ and Choi YH: Naringenin up-regulates the expression of death receptor 5 and enhances TRAIL-induced apoptosis in human lung cancer A549 cells. Mol Nutr Food Res 55: 300-309, 2011.

6. Oyagbemi AA, Saba AB and Azeez OI: Molecular targets of [6]-gingerol: Its potential roles in cancer chemoprevention. Biofactors 36: 169-178, 2010.

7. Shukla Y and Singh M: Cancer preventive properties of ginger: A brief review. Food Chem Toxicol 45: 683-690, 2007.

8. Lee TY, Lee KC, Chen SY and Chang HH: 6-gingerol inhibits ROS and iNOS through the suppression of PKC-alpha and NF-kappaB pathways in lipopolysaccharide-stimulated mouse macrophages. Biochem Biophys Res Commun 382: 134-139, 2009.

9. Bode AM, Ma WY, Surh YJ and Dong Z: Inhibition of epidermal growth factor-induced cell transformation and activator protein 1 activation by [6]-gingerol. Cancer Res 61: 850-853, 2001.

10. Chakraborty D, Bishayee K, Ghosh S, Biswas R, Mandal SK and Khuda-Bukhsh AR: [6]-gingerol induces caspase 3-dependent apoptosis and autophagy in cancer cells: Drug-DNA interaction and expression of certain signal genes in HeLa cells. Eur J Pharmacol 694: 20-29, 2012.

11. Lee E and Surh YJ: Induction of apoptosis in HL-60 cells by pungent vanilloids, [6]-gingerol and [6]-paradol. Cancer Lett 134: 163-168, 1998.

12. Kroemer G, Mariño G and Levine B: Autophagy and the integrated stress response. Mol Cell 40: 280-293, 2010.

13. Mizushima N: Autophagy: process and function. Genes Dev 21: 2861-2873, 2007.

14. Klionsky DJ, Abeliovich H, Agostinis P, Agrawal DK, Aliev G, Askew DS, Baba M, Baehrecke EH, Bahr BA, Ballabio A, et al: Guidelines for the use and interpretation of assays for monitoring autophagy in higher eukaryotes. Autophagy 4: 151-175, 2008

15. Nakatogawa $H$, Ichimura $Y$ and Ohsumi Y: Atg8, a ubiquitin-like protein required for autophagosome formation, mediates membrane tethering and hemifusion. Cell 130: 165-178, 2007. 
16. Xie Z, Nair U and Klionsky DJ: Atg8 controls phagophore expansion during autophagosome formation. Mol Biol Cell 19: 3290-3298, 2008.

17. Bjørkøy G, Lamark T, Brech A, Outzen H, Perander M, Overvatn A, Stenmark H and Johansen T: p62/SQSTM1 forms protein aggregates degraded by autophagy and has a protective effect on huntingtin-induced cell death. J Cell Biol 171: 603-614, 2005.

18. Mizushima N and Yoshimori T: How to interpret LC3 immunoblotting. Autophagy 3: 542-545, 2007.

19. Livesey KM, Tang D, Zeh HJ and Lotze MT: Autophagy inhibition in combination cancer treatment. Curr Opin Investig Drugs 10: 1269-1279, 2009.

20. Liu L, Yang M, Kang R, Wang Z, Zhao Y, Yu Y, Xie M, Yin X, Livesey KM, Lotze MT, et al: HMGB1-induced autophagy promotes chemotherapy resistance in leukemia cells. Leukemia 25: 23-31, 2011.

21. White E and DiPaola RS: The double-edged sword of autophagy modulation in cancer. Clin Cancer Res 15: 5308-5316, 2009.

22. Apel A, Herr I, Schwarz H, Rodemann HP and Mayer A: Blocked autophagy sensitizes resistant carcinoma cells to radiation therapy. Cancer Res 68: 1485-1494, 2008.

23. Carew JS, Espitia CM, Esquivel JA II, Mahalingam D, Kelly KR, Reddy G, Giles FJ and Nawrocki ST: Lucanthone is a novel inhibitor of autophagy that induces cathepsin D-mediated apoptosis. J Biol Chem 286: 6602-6613, 2011.

24. Boya P, González-Polo RA, Casares N, Perfettini JL, Dessen P, Larochette N, Métivier D, Meley D, Souquere S, Yoshimori $\mathrm{T}$, et al: Inhibition of macroautophagy triggers apoptosis. Mol Cell Biol 25: 1025-1040, 2005.

25. Sotelo J, Briceño E and López-González MA: Adding chloroquine to conventional treatment for glioblastoma multiforme: A randomized, double-blind, placebo-controlled trial. Ann Intern Med 144: 337-343, 2006.

26. Goldberg SB, Supko JG, Neal JW, Muzikansky A, Digumarthy S, Fidias P, Temel JS, Heist RS, Shaw AT, McCarthy PO, et al: A phase I study of erlotinib and hydroxychloroquine in advanced non-small-cell lung cancer. J Thorac Oncol 7: 1602-1608, 2012.

27. Poole B and Ohkuma S: Effect of weak bases on the intralysosomal $\mathrm{pH}$ in mouse peritoneal macrophages. J Cell Biol 90: 665-669, 1981.
28. Fan C, Wang W, Zhao B, Zhang S and Miao J: Chloroquine inhibits cell growth and induces cell death in A549 lung cancer cells. Bioorg Med Chem 14: 3218-3222, 2006.

29. Jiang PD, Zhao YL, Deng XQ, Mao YQ, Shi W, Tang QQ, Li ZG, Zheng YZ, Yang SY and Wei YQ: Antitumor and antimetastatic activities of chloroquine diphosphate in a murine model of breast cancer. Biomed Pharmacother 64: 609-614, 2010.

30. Yoon YH, Cho KS, Hwang JJ, Lee SJ, Choi JA and Koh JY: Induction of lysosomal dilatation, arrested autophagy, and cell death by chloroquine in cultured ARPE-19 cells. Invest Ophthalmol Vis Sci 51: 6030-6037, 2010.

31. Mahalingam D, Szegezdi E, Keane M, de Jong S and Samali A: TRAIL receptor signalling and modulation: Are we on the right TRAIL? Cancer Treat Rev 35: 280-288, 2009.

32. Yoshikawa M, Hatakeyama S, Chatani N, Nishino $Y$ and Yamahara J: Qualitative and quantitative analysis of bioactive principles in Zingiberis Rhizoma by means of high performance liquid chromatography and gas liquid chromatography. On the evaluation of Zingiberis Rhizoma and chemical change of constituents during Zingiberis Rhizoma processing. Yakugaku Zasshi 113: 307-315, 1993 (In Japanese).

33. Nakazawa $\mathrm{T}$ and Ohsawa K: Metabolism of [6]-gingerol in rats. Life Sci 70: 2165-2175, 2002

34. Habib SH, Makpol S, Abdul Hamid NA, Das S, Ngah WZ and Yusof YA: Ginger extract (Zingiber officinale) has anti-cancer and anti-inflammatory effects on ethionine-induced hepatoma rats. Clinics (São Paulo) 63: 807-813, 2008.

35. Singh K, Sharma A, Mir MC, Drazba JA, Heston WD, Magi-Galluzzi C, Hansel D, Rubin BP, Klein EA and Almasan A: Autophagic flux determines cell death and survival in response to Apo2L/TRAIL (dulanermin). Mol Cancer 13: 70, 2014.

36. Park KJ, Lee SH, Kim TI, Lee HW, Lee CH, Kim EH, Jang JY, Choi KS, Kwon MH and Kim YS: A human scFv antibody against TRAIL receptor 2 induces autophagic cell death in both TRAIL-sensitive and TRAIL-resistant cancer cells. Cancer Res 67: 7327-7334, 2007.

37. Ishiguro K, Ando T, Maeda O, Ohmiya N, Niwa Y, Kadomatsu K and Goto $\mathrm{H}$ : Ginger ingredients reduce viability of gastric cancer cells via distinct mechanisms. Biochem Biophys Res Commun 362: 218-223, 2007. 